Estudios Constitucionales, Año 17, № 2, 2019, pp. 121-140

ISSN 07180195

Centro de Estudios Constitucionales de Chile Universidad de Talca

"Responsabilidad corporativa en procesos transicionales de paz: Entre la judicialización

y la autorregulación. Elementos de análisis desde el caso colombiano"

Jenner Alonso Tobar Torres

\title{
RESPONSABILIDAD CORPORATIVA EN PROCESOS TRANSICIONALES DE PAZ: ENTRE LA JUDICIALIZACIÓN Y LA AUTORREGULACIÓN. ELEMENTOS DE ANÁLISIS DESDE EL CASO COLOMBIANO*
}

\author{
CORPORATE ACCOUNTABILITY IN TRANSITIONAL PEACE PROCESSES: \\ BETWEEN JUDICIALIZATION AND SELF-REGULATION. ELEMENTS \\ OF ANALYSIS FROM THE COLOMBIAN CASE
}

\author{
Jenner Alonso Tobar Torres* \\ Docente investigador de la Facultad de Derecho \\ de la Universidad Libre de Colombia \\ jenner.tobar@unilibre.edu.co
}

RESUMEN: La actividad empresarial es un factor clave a tomar en cuenta al momento de adelantar procesos transicionales de paz. Las experiencias internacionales han mostrado que en contextos de largos conflictos armados, las empresas y corporaciones pueden desarrollar actividades con las cuales, de forma directa o indirecta, se afectan derechos de las comunidades y se incurren en violaciones de Derechos Humanos. En tal sentido, un modelo adecuado de justicia transicional debe incorporar mecanismos mediante los cuales se garanticen los derechos de las víctimas con relación a la investigación, juzgamiento y sanción de eventuales violaciones de Derechos Humanos en que incurran las empresas dentro del territorio en conflicto. El presente artículo muestra las experiencias internacionales en la materia, a partir de instrumentos de autorregulación, por una parte, y de judicialización, por otra parte. Además, se efectúa un análisis del asunto en torno a la experiencia que actualmente se desarrolla en la justicia transicional colombiana.

ABSTRACT: Business activity is a key factor to take into account in transitional peace processes. International experiences have shown that in contexts of long-armed conflicts, companies and corporations can develop activities with which, directly or indirectly, human rights violations are incurred. In this regard, an adequate model of transitional justice must incorporate mechanisms through which the victim's rights are guaranteed in relation to the investigation, prosecution and punishment of possible

\footnotetext{
* Este artículo recoge la presentación efectuada por el autor en el IV Congreso Internacional De Derechos Humanos celebrado en la Universidad de Coimbra (Portugal) entre el 16 y 18 de octubre de 2019. Este trabajo es un producto de nuevo conocimiento articulado al Grupo de investigación de Derecho Privado y del proceso "Gustavo Vanegas Torres" de la Universidad Libre de Colombia.

** Abogado. Doctor en Derecho de la Universidad de Buenos Aires, Magíster en Derecho de la Universidad Nacional de Colombia y Especialista en Derecho Constitucional de la Universidad Externado de Colombia.

Artículo recibido el 7 de octubre de 2019 y aprobado el 15 de noviembre de 2019.
} 
violations of Human Rights incurred by companies. This paper presents international experiences in this field, which are based on self-regulation instruments, on the one hand, and judicialization processes, on the other hand. In addition, an analysis of the issue is carried out around the experience currently being developed in Colombian transitional justice.

Palabras Clave: Responsabilidad corporativa, procesos de paz, postconflicto, Proceso de paz en Colombia.

KEYWORDS: Corporate accountability, peace processes, post-conflict, Colombia peace process.

\section{INTRODUCCIÓN}

Teniendo en cuenta que las actividades de las empresas transnacionales abarcan múltiples áreas de actuación y de influencia, desde hace varios años ha surgido una preocupación hacia las demandas de responsabilidad frente a los actores del mercado, exigiéndose que las empresas transnacionales asuman compromisos de respeto hacia los Derechos Humanos de las comunidades donde sus actividades tienen impacto.

En este contexto, el autocontrol y autodisciplina de las profesiones se viene consolidando como una forma de autorregulación normativa, a través de la creación de diversos códigos éticos, códigos de conducta, auditorias y certificaciones de responsabilidad social, guías de inversión éticas, entre otros, en áreas como los medios de comunicación, la publicidad y la ciencia, donde las codificaciones deontológicas juegan un papel muy importante para responder desafíos éticos que el funcionamiento de tales campos plantea.

De hecho, ante la evidencia de los impactos sociales, laborales y ambientales que el desarrollo de algunas industrias genera, amplia y rápidamente divulgados por los medios de comunicación globales, los consumidores han comenzado a efectuar un control activo de tales impactos, adoptándolo como un factor relevante de elección en el mercado.

En varias latitudes la responsabilidad social empresaria ha logrado importantes cambios en el comportamiento empresarial, ha generado conciencia de que el consumo no es una actividad desligada de la producción, y ha evidenciado un importante avance en que las empresas acepten la responsabilidad por sus actividades.

Sin embargo, en espacios donde se desarrollan procesos de justicia transicional y donde se investigan violaciones de Derechos Humanos, los estándares de control hacia la actividad de las empresas debe ser más alto, lo que se acentúa cuando se pretende consolidar verdad, justicia y reparación frente las víctimas. 
En estos escenarios resulta esencial establecer el rol que las empresas han desempeñado como actores directos o indirectos del conflicto, junto con el alcance de su participación. Para lograr estos objetivos los sistemas de justicia transicional pueden adoptar $-\mathrm{y}$ han adoptado- enfoques de judicialización de los actores corporativos. No obstante, en el caso colombiano la experiencia muestra que la capacidad investigativa y punitiva del Estado se ha visto, en términos generales, desbordada por la amplitud del fenómeno de participación multinivel de las empresas en hechos relacionados con el conflicto armado.

Así las cosas, la responsabilidad corporativa en procesos transicionales se ha buscado consolidar a través de mecanismos tanto de autorregulación como de judicialización. A continuación, se expondrán las características principales de cada uno de estos enfoques para luego efectuar un análisis de los procesos transicionales que se han desarrollado recientemente en el Estado colombiano.

\section{LA AUTORREGULACIÓN EMPRESARIAL EN CONTEXTOS TRANSICIONALES}

Uno de los mayores déficits en contextos de justicia transicional ha sido la poca atención que en muchos casos se ha brindado a la violencia económica en los conflictos armados. Experiencias internacionales han mostrado que los aspectos económicos de los conflictos no siempre han sido tenidos en cuenta como eje transversal de los mismos, lo que puede traer consecuencias para la obtención de una paz estable y duradera en el postconflicto ${ }^{2}$.

Esto ha generado que en ocasiones no se adecuen modelos aptos para abordar de manera satisfactoria las complejidades de los conflictos, incluyendo la totalidad de sus causas, las dinámicas de guerra y la pluralidad actores y víctimas. Esta situación resulta evidente respecto al rol de empresas, corporaciones y particulares vinculados con el sector productivo, pues en muchos casos el foco de atención en la justicia transicional se ha colocado sobre la responsabilidad del Estado de reparar a las víctimas, dejando de lado la responsabilidad de estos particulares en las dinámicas del conflicto ${ }^{3}$, por lo que se ha señalado que "la justicia transicional prácticamente ha ignorado la responsabilidad corporativa en violaciones de derechos humanos en las dictaduras y los conflictos armados" 4 .

2 Sharp (2014), p. 11.

3 Sandoval y Surfleet (2013), p. 93.

4 PAYNe (2017), p. 22. 
Está fuera de discusión que en sociedades que atraviesan fenómenos de conflictos armados, las empresas, corporaciones y particulares vinculados con el sector productivo son actores claves en varios niveles. En primer lugar, han sido víctimas de violaciones a derechos humanos o económicos. Por otra parte, las experiencias han mostrado que actores de este tipo también han participado de forma directa o indirecta en las dinámicas del conflicto.

Así las cosas, son numerosas las voces que han reclamado la creación y desarrollo de obligaciones de los particulares respecto a su observancia de los Derechos Humanos, lo que resulta especialmente relevante en escenarios de conflictos armados, por lo cual se han establecido diversos mecanismos para lograr que estos actores se involucren activamente en los procesos de justicia transicional.

De esta forma, en el contexto internacional existe una clara tendencia a reconocer y establecer obligaciones "morales y éticas" de las empresas en el respeto de los Derechos Humanos 5 y, para ello, el mecanismo más acogido por los actores privados para comprometerse con el respeto de los Derechos Humanos es a través de instrumentos legales no vinculantes y de cumplimiento voluntario, o en otras palabras, a través de instrumentos de soft law productos de los ejercicios de autorregulación empresarial.

La autorregulación corporativa es un fenómeno que ha sido profusamente estudiado en las últimas décadas a partir de su crecimiento exponencial en diversas áreas donde otrora el Estado ejercía como único agente regulador, de forma que los particulares comparten escenarios de producción normativa con el Estado. Así las cosas, se puede considerar la autorregulación como una especie de regulación indirecta desarrollada por actores distintos al Estado, incluso en ocasiones promovida por este, que de ningún modo representa la ausencia de reglas o pautas de conducta ${ }^{6}$.

Como resultado de la autorregulación surgen contenidos normativos que son aplicados voluntariamente y controlados por los propios autorreguladores, y aunque en varios casos no sean reglas obligatorias estas "tienen un valor regulatorio de facto inmenso porque quien no se atiene a ellas (v. gr. Normas de calidad de producción, de protección medioambiental, etiquetas verdes, etc.) corre el riesgo

5 PAYNe (2017), p. 27.

6 Tobar (2017), p. 136. 
de ser arrojado fuera de los mercados o, desde luego, como minimo, de tener que competir en condiciones de absoluta inferioridad'7.

El resultado normativo de la autorregulación ha sido comúnmente calificado como soft law, entendiendo por tal el conjunto de normas que no son impuestas coercitivamente recurriendo a la fuerza pública, pero que pueden resultar vinculantes por la aceptación voluntaria de los sujetos pasivos, quienes por diferentes razones aceptan tales reglas, las cuales pueden emanar tanto del Estado como de actores no estatales. Así, es definitorio de estas normas que tanto su adopción como su cumplimiento es voluntario, lo que da lugar al surgimiento de relaciones de complementariedad frente la regulación estatal, a través de relaciones de cooperación o competencia, horizontales o verticales, formales o informales ${ }^{8}$.

Tratándose de la responsabilidad de las empresas respecto a la observancia y respeto de los Derechos Humanos, existen varios instrumentos internacionales no vinculantes ${ }^{9}$, pero ninguno de ellos ha sido especialmente diseñado o pensado para la operación de empresas en zonas de conflicto. No obstante, de tales instrumentos se puede colegir obligaciones de las empresas como apoyar y respetar la protección de los derechos humanos, evitar incurrir en complicidad de violaciones de los derechos humanos, desarrollar el principio de debida diligencia, respetar las normas del derecho internacional humanitario, entre otros.

En tal sentido, autores como Sandoval y Suerfleet (2014) afirman que estos instrumentos, aunque no vinculantes, son un importante marco de referencia para los involucrados en procesos de justicia transicional pues explicita las obligaciones corporativas, en especial aquellas tendientes a proveer remedios efectivos a nivel sustancial y procesal. Sin embargo, es notoria la ausencia en estos instrumentos de mecanismos de compensación y responsabilidad para aquellas empresas responsables de violaciones del derecho internacional humanitario o derechos humanos ${ }^{10}$.

En efecto, pese a su popularidad entre el sector empresarial, estos instrumentos autorregulatorios han sido cuestionados por sus limitaciones, entre las

\footnotetext{
7 MuÑoz (2010), p. 124.

8 Tobar (2017), p. 168.

9 A modo enunciativo pueden mencionarse los Principios Rectores de la ONU sobre Empresas y Derechos Humanos (Principios Ruggie), el Pacto Global de Naciones Unidas, la Guía de Responsabilidad Social ISO 26000, las Directrices de la Organización para la Cooperación y el Desarrollo Económicos para Empresas Multinacionales (OCDE), entre otras.

10 Sandoval y Surfleet (2014), p. 99.
} 
que se destaca la ausencia de un monitoreo independiente que garantice que no son simples declaraciones de principios empresariales, la poca participación en su elaboración de los interesados directos -víctimas del conflicto, trabajadores, asociaciones ambientales, etc.-, entre otros. Por ello, hay quienes consideran que en la práctica, los programas de responsabilidad social empresaria y los códigos de conducta no comprometen en nada a las compañías multinacionales, quienes por su cuenta deciden qué firmar, cómo hacerlo y qué cumplir ${ }^{11}$.

\section{LA JUDICIALIZACIÓN EMPRESARIAL EN CONTEXTOS TRANSICIONALES}

En contextos transicionales y bajo las reglas del Derecho Internacional $\mathrm{Hu}-$ manitorio, se considera que, pese a la ausencia de instrumentos internacionales coercitivos que impongan de forma directa obligaciones a las empresas, aquellas corporaciones que:

"operan en zonas de conflicto, asi como su personal, corren ciertos riesgos jurídicos, que van desde su responsabilidad penal por cometer o ser cómplices de un crimen de guerra, a su responsabilidad civil por daños y perjuicios. El derecho internacional humanitario dispone que, no sólo los autores de las violaciones, sino también sus superiores, podrán ser responsables penalmente de la comisión de un crimen de guerra"12.

Es claro que individuos que trabajan para corporaciones pueden estar implicados en la comisión de conductas punibles susceptibles de persecución, juicio y condena. Sin embargo, una de las dificultades prácticas para lograr una efectiva responsabilización de las empresas, es la ausencia en el derecho penal internacional de instrumentos que permitan perseguirlas.

Si bien es posible reclamar responsabilidad penal de los individuos, para muchos autores esto no es satisfactorio en contextos de justicia transicional, pues se omite que los individuos actuaron como resultado de su rol dentro de la empresa ${ }^{13}$ y evita desmantelar las estructuras económicas que hicieron posible tales crímenes, generando un impacto negativo en la posibilidad de evitar las mismas situaciones en el futuro ${ }^{14}$.

11 Hernández Zubizarreta, J. y Ramiro, P. (2015), p. 48.

12 Comité Internacional de la Cruz Roja, (2006).

13 Payne (2017), p. 28.

14 Sandoval, Filippini y Vidal (2014), p. 15. 
En contextos transicionales esta realidad es aún más compleja pues se ha reconocido ampliamente el potencial y la importancia que la actividad empresarial tiene en escenarios de postconflicto en áreas como la reconstrucción de infraestructura, la generación de empleo, la implementación de mecanismos de inserción laboral y social de los actores del conflicto, entre otros ${ }^{15}$. Así, teniendo en cuenta la importancia del rol empresarial en contextos de postconflicto, "a trade off appears to be required: in exchange for their contributions to a coutry's económic recovery, corporations and their CEOs are not prosecuted" 16.

Lo anterior no significa que en contextos de justicia transicional se haya renunciado a la persecución de las actividades criminales de las empresas. Las experiencias internacionales reflejan que ha sido a través de la implementación de mecanismos estatales de reparación -judiciales y extrajudiciales- que las empresas han sido vinculadas a la justicia transicional.

Respecto a los mecanismos judiciales quizá los más relevantes han sido los tribunales de justicia transicional creados especialmente para la investigación y sanción de los crímenes cometidos durante los conflictos ${ }^{17}$, pero las empresas también se han visto vinculadas en investigaciones adelantadas en tribunales civiles $^{18}$, tribunales agrarios ${ }^{19}$ o laborales. De hecho, estudios internacionales advierten que la utilización de mecanismos judiciales tendientes a exigirles a

\footnotetext{
15 Prandi y Lozano (2010).

16 Sandoval, Filippini y Vidal (2014), p. 15.

17 Como ejemplo, puede mencionarse la Jurisdicción especial para la paz (JEP) que se creó en Colombia como resultado del "Acuerdo final para la terminación del conflicto y la construcción de una paz estable y duradera", entre el gobierno colombiano y las FARC-EP. Como se desarrollará más adelante, este tribunal de justicia transicional tiene ciertas competencias respecto a terceros civiles no combatientes que voluntariamente se acojan a dicho tribunal.
}

18 Bajo las prerrogativas de Ley de Demandas por Hechos Ilícitos contra Extranjeros (ATCA por su sigla en inglés) se han intentado acciones de este tipo antes tribunales estadounidenses. El caso Khulumani, en el cual se demandaron varias corporaciones de ese país por su responsabilidad en las violaciones de derechos humanos cometidas en Sudáfrica durante el apartheid, y el caso Kiobel, en el cual se persiguió la responsabilidad de la multinacional Shell por complicidad en crimines cometidos en Nigeria, son dos de los casos más relevantes en esta materia. En el primer caso, las partes alcanzaron un acuerdo conciliatorio. En el caso Kiobel, un reciente fallo denegó las pretensiones de la demanda, señalando un precedente que, a juicio de varios autores, limita seriamente la posibilidad de las víctimas de empresas americanas en suelo extranjero para lograr el resarcimiento de sus daños ante cortes federales estadounidenses (MeEtali y BonitA, 2014).

19 Ejemplo es el caso colombiano, en donde, a partir de la implementación de la Política Pública de Restitución de Tierras y Territorios en Colombia, se persigue el resarcimiento judicial del despejo de tierras sufrido por las víctimas del conflicto armado colombiano. En algunos de estos procesos se han identificado la participación directa o indirecta de actores económicos (MiCHALOWSKI et al., 2018). 
las empresas rendición de cuentas por su responsabilidad en violaciones de los derechos humanos, dentro de contextos de justicia transicional, va en aumento, a pesar de las barreras económicas, geográficas y judiciales que las víctimas deben enfrentar cuando se proponen acudir ante cortes locales o extranjeras para el resarcimiento de sus derechos ${ }^{20}$.

Entre los mecanismos estatales extrajudiciales probablemente el más relevante y utilizado ha sido la creación de comisiones de la verdad. Desde 1984 cuando la Comisión Nacional sobre la Desaparición de Personas -Conadep- asumió la labor de investigar las violaciones de Derechos Humanos durante la dictadura argentina, estas experiencias se han replicado alrededor del mundo. En contextos transicionales el conocimiento de la verdad, además de ser un derecho humano de las víctimas, es un insumo necesario para alcanzar lazos de reconciliación entre los actores del conflicto y la sociedad ${ }^{21}$, además, estas comisiones pueden fortalecer la paz y la seguridad a largo plazo abordando las dimensiones relacionadas con los derechos económicos, sociales y culturales de los conflictos.

En efecto, estas comisiones tienen el potencial para desentrañar el contexto y las causas del conflicto, así como para indagar sobre las violaciones a Derechos Humanos que tuvieron lugar, identificando responsabilidades y las estructuras sociales que rodearon el conflicto. Sin embargo, las experiencias internacionales han mostrado grandes debilidades cuando se trata de abordar el tema de la responsabilidad empresarial.

Con algunas experiencias más satisfactorias que otras ${ }^{22}$, en términos generales se puede afirmar que las comisiones de verdad, al ser instituciones políticamente débiles, con pocos recursos humanos y económicos, y con una experticia dirigida más hacia la responsabilidad estatal, no han logrado abordar de forma contundente la responsabilidad corporativa ${ }^{23}$, en ningún caso, estas comisiones han elaborado criterios para evaluar dicha responsabilidad en los conflictos ${ }^{24}$, y salvo el caso sudafricano, en aquellas experiencias donde se han establecido

20 VAn de SAndt y Moor (2017), p. 170.

21 Sharp (2014), p. 84.

22 Quizá la experiencia más exitosa en este campo es la Comisión de Verdad y Reconciliación de Sudáfrica, la cual logró colocar en el debate público el papel de las empresas en el desarrollo del conflicto. Se puede mencionar también la comisión de la verdad adelantada en Liberia, en donde se aludió a la responsabilidad de algunas corporaciones en la comisión de crímenes económicos y violaciones de Derechos Humanos.

23 Sandoval, Filippini y Vidal (2014), p. 18.

24 MichalowsKi et al. (2018), p. 147. 
ciertas responsabilidades, no se han generado mecanismos de reparación o compensación a las víctimas ${ }^{25}$.

A pesar de estas limitaciones, muchos consideran que las comisiones de la verdad ofrecen un gran escenario para establecer responsabilidades corporativas bajos las necesidades particulares que requieren las sociedades que atraviesan escenarios de conflicto y postconflicto ${ }^{26}$. Por supuesto ello exige el diseño de comisiones de verdad independientes política y económicamente, en contacto directo con los grupos afectados por los crímenes corporativos, con capacidad para generar reparaciones (no solo económicas sino restaurativas) a cargo de las empresas, y por supuesto Estados con capacidad y voluntad de implementar sus recomendaciones ${ }^{27}$.

\section{LA RESPONSABILIDAD EMPRESARIAL EN LA JUSTICIA TRANSICIONAL COLOMBIANA. ENTRE AUTORREGULACIÓN Y JUDICIALIZACIÓN \\ - El escenario de Justicia y Paz}

Como se desarrolló en páginas anteriores, en contextos de conflictos armados es posible que las empresas se vean involucradas a través de su participación directa o indirecta en violaciones de Derechos Humanos. El conflicto colombiano no ha sido la excepción, y durante su largo desarrollo se han conocido diversos casos de crímenes con participación de empresas nacionales y multinacionales.

El caso colombiano tiene como particularidad la continua lucha de los actores del conflicto por el control de ciertas regiones con valor estratégico para la explotación económica de algún bien o recurso natural. Asimismo, ha sido recurrente la alianza entre actores empresariales, élites locales y grupos armados para establecer agendas comunes que han llevado a la comisión de múltiples actos de violencia política y económica, masacres, actos de despojo de tierras, y en general, violaciones de Derechos Humanos, con participación, conocimiento o patrocinio de actores corporativos ${ }^{28}$. Para tener una idea de la magnitud del fenómeno se pueden revisar algunas cifras de las investigaciones y sentencias del sistema transicional de Justicia y Paz.

25 Sandoval y Surfleet (2014), p. 112.

26 Michalowski y Carranza (2014), p. 249.

27 Koska (2016), pp. 59-60.

28 Sánchez León y Marín López (2017), p. 135. 
Como resultado de las negociaciones entre el gobierno nacional y los grupos de autodefensas que operaron en el país, se desarrolló un proceso transicional a partir de la promulgación de la Ley No 975 de 2005, conocida como Ley de justicia y paz. Unas de las características del sistema transicional creado con esta ley fue que el modelo de judicialización diferenciado cobijó únicamente a los excombatientes, dejando por fuera a los terceros civiles que pudieran tener algún tipo de participación en el conflicto. Por este motivo, los jueces encargados de aplicar la Ley de Justicia y Paz carecieron de competencia para judicializar terceros no combatientes como las empresas.

No obstante, con la modificación efectuada por la Ley No 1.592 de 2012, se introdujo la necesidad y deber de establecer las redes de apoyo y financiación de los grupos armados, lo cual, si bien no le da competencia directa a estos jueces para el juzgamiento de terceros, sí permite que en las investigaciones y en la construcción de contextos se indague sobre el rol de los terceros en estos aspectos, siendo particularmente importante esta labor para establecer potenciales escenarios de responsabilidad corporativa. Además, esta modificación permitió que algunos jueces adoptaran interpretaciones bajo las cuales, "en caso de encontrar a una persona que no fuera parte orgánica de la estructura paramilitar, pero hizo parte de una esfera de poder económico, y se evidencia que su aporte fue funcional y efectivo para la expansión, consolidación y beneficio de la estructura armada, el despacho considera que dicho sujeto debería responder como autor mediato de los hechos cometidos por la estructura paramilitar durante el tiempo en que el aporte fue funcional a la organización"29.

En sus investigaciones y sentencias, los jueces de justicia y paz efectuaron la construcción de contextos (buscando identificar patrones de macrocriminalidad) y recopilaron diversidad de declaraciones y pruebas, en donde se efectuaron múltiples menciones a actores económicos como partícipes del conflicto. En un estilo adelantado por el Centro Internacional de Toledo para la Paz (CITpax)-Colombia (2018), se estableció que "en 20 de las 51 sentencias proferidas en Justicia y Paz, equivalentes al 39\% del total, se identificaron un total de 187 empresas y empresarios señalados como parte de las redes de apoyo a grupos paramilitares" 30 , señala este estudio que, del total de menciones, el $65 \%$ fueron

29 Michalowski et al. (2018), p. 114.

30 Centro Internacional de Toledo para la Paz (CiTpax)-Colombia (2018), p. 47. 
a personas jurídicas y el restante $35 \%$ hacía referencia a empresarios personas naturales.

Por su parte, en una investigación desarrollada por el Centro de Estudios de Derecho, Justicia y Sociedad, Dejusticia, se estableció que "a corte de marzo de 2017, se encontraron un total de 39 sentencias en las que se menciona a actores económicos como presuntos actores en el conflicto" 31 , agrega este estudio que del total de menciones a empresarios (766 menciones), el 40,08\% (307 menciones), correspondieron a personas jurídicas y de este grupo solo el 8,14\% (25 menciones) recayeron sobre empresas multinacionales (pág. 41).

Entre las conductas que se endilgan a los actores económicos con relación al desarrollo del conflicto se encuentran el apoyo económico o financiero a los actores armados, el despojo de tierras, y el apoyo logístico a los mismos entre las que se comprenden actividades como venta o facilitación de helicópteros y transporte, préstamo de fincas, entrega de medicamentos a las estructuras paramilitares, entrega de armas, uso de influencias para fines privados y políticos, entre otros (Michalowski et al., 2018).

Ahora bien, teniendo en cuenta que dentro del sistema transicional de justicia y paz los jueces no tienen competencia para enjuiciar a los terceros civiles no combatientes, al encontrar una mención a estos sujetos, el juez debe establecer si existe mérito suficiente o no para promover una investigación contra el involucrado, para lo cual debe compulsar copia de la investigación a los órganos de la jurisdicción ordinaria para que allí se adelante la investigación y juzgamiento correspondiente.

En este sentido, no en todos los casos donde existieron menciones a actores económicos dentro de las investigaciones de justicia y paz, los jueces determinaron la compulsa de copias. En un reciente comunicado la Fiscalía General de la Nación (23 de mayo de 2019), informó que al efectuarse un inventario detallado de las compulsas de copias efectuadas por Justicia y Paz que reposan en la entidad y que vincularían a terceros civiles a los diferentes hechos ilícitos asociados al conflicto armado en Colombia, se encontró que en total se han efectuado 16.772 compulsas de copias respecto de 1.563 terceros civiles, agentes del Estado no combatientes e integrantes de organizaciones al margen de la ley. En este informe se señala que se entiende por terceros civiles "empresarios, comerciantes, profesionales liberales y empresas de distintas actividades econó-

31 Michalowski et al. (2018), p. 40. 
micas, con énfasis en los sectores ganadero, agropecuario y de hidrocarburos", y señala que sobre este grupo en particular se profirieron 311 compulsa de copias. El comunicado no especifica el estado actual de las investigaciones, de tal forma que se desconoce cuántas investigaciones están en curso, cuantas están en juicio o cuántas han sido archivadas.

Es innegable que en el sistema transicional de Justicia y Paz se han efectuado importantes esfuerzos para identificar patrones y conductas de responsabilidad corporativa en el conflicto colombiano. Sin embargo, esto se ha visto seriamente limitado a partir del diseño mismo del modelo de justicia transicional en tanto la investigación y judicialización de estos actores no corresponde a la justicia transicional, sino que fue la justicia penal ordinaria quien mantuvo la competencia respecto de terceros civiles como las empresas, por lo cual todo hallazgo o evidencia debe ser remitido a la justicia ordinaria, afectando claramente la continuidad e integridad de los procesos. Es por ello que varios analistas han establecido que existe una evidente ruptura entre justicia transicional y la justicia ordinaria ${ }^{32}$. A esto se agrega "los impedimentos procesales con respecto a la investigación de "empresas" por responsabilidad penal, se suman las dificultades probatorias para demostrar móviles relacionados con su actividad comercial para la presunta pertenencia a redes de apoyo a grupos paramilitares" 33 .

Si bien es cierto, se han presentado algunos casos emblemáticos de éxito en la justicia ordinaria ${ }^{34}$, lo cierto es que los mejores avances en la judicialización de la responsabilidad corporativa se han dado apenas en la identificación de conductas de este tipo dentro de los contextos elaborados por los jueces de justicia y paz, sin que ello signifique por sí solo algún tipo de responsabilidad judicial para las empresas. Considerando el número de compulsa de copias para la investigación de empresarios, se puede afirmar que la justicia penal ordinaria no ha desarrollado un proceso de judicialización efectivo respecto a la magnitud del fenómeno de responsabilidad empresarial en el contexto del conflicto colombiano.

32 Michalowski et al. (2018).

33 Centro Internacional de Toledo para la Paz (CITpax)-Colombia (2018), p. 58.

34 Casos emblemáticos como los de Urapalma, el Fondo Ganadero de Córdoba, justicia y paz, el caso de la empresa ítalo-argentina de ingeniería Simic, son algunos ejemplos de casos donde las justicia penal ordinaria colombiana ha alcanzado la judicialización de actores empresariales por su participación en distintos niveles del conflicto armado. Cfr. Van de Sandt y Moor (2017); Michalowski y Cardona (2015); BERNAL (2017); entre otros. 
- El escenario de la Justicia Especial para la Paz JEP

En el año 2016 se suscribió entre el gobierno colombiano y el grupo armado FARC-EP, el Acuerdo final para la terminación del conflicto y la construcción de una paz estable y duradera, que puso fin a un conflicto armado de más de 60 años. Como resultado del AF se contempló la creación de un órgano de justicia transicional denominada Jurisdicción Especial para la Paz (JEP).

"La Jurisdicción Especial para la Paz (JEP) es el componente de justicia del Sistema Integral de Verdad, Justicia, Reparación y no Repetición (SIVJRNR), creado por el Acuerdo de Paz entre el Gobierno Nacional y las Farc-EP. La JEP tiene la función de administrar justicia transicional y conocer de los delitos cometidos en el marco del conflicto armado que se hubieran cometido antes del 1 de diciembre de 2016. La existencia de la JEP no podrá ser superior a 20 años. La JEP fue creada para satisfacer los derechos de las victimas a la justicia, ofrecerles verdad y contribuir a su reparación, con el propósito de construir una paz estable y duradera" 35.

En relación con las facultades de esta jurisdicción para perseguir actos de terceros civiles no combatientes, la enmienda constitucional que dio lugar a la creación de la JEP (Acto Legislativo 01 de 2017) estableció la posibilidad de que estos terceros se sometan voluntariamente a la JEP:

"siempre que cumplan con las condiciones establecidas de contribución a la verdad, reparación y no repetición", pero además reiteró la competencia de esta jurisdicción para hacer comparecer a "aquellos terceros que hubieran tenido una participación activa o determinante en la comisión de los siguientes delitos: el genocidio, delitos de lesa humanidad, los graves crimenes de guerra -esto es, toda infracción del Derecho Internacional Humanitario cometida de forma sistemática-, la toma de rehenes u otra privación grave de la libertad, la tortura, las ejecuciones extrajudiciales, la desaparición forzada, el acceso carnal violento y otras formas de violencia sexual, la sustracción de menores, el desplazamiento forzado, además del reclutamiento de menores, todo ello conforme a lo establecido en el Estatuto de Roma. Se entiende por participación determinante para estos efectos aquella acción eficaz y decisiva en la realización de los delitos enunciados" 36 .

Con este artículo, a la JEP se le otorgaba competencia para investigar, juzgar y sancionar, dentro de los parámetros del sistema transicional, a los terceros que

35 Justicia Especial para la Paz JeP (2019).

36 República de Colombia, Acto Legislativo 01 de 2017. Artículo 16. 
cumpliendo los fines del SIVJRNR se sometieran voluntariamente a ella para recibir los beneficios del sistema, pero además mantenía la competencia para hacer comparecer a los terceros responsables de los crímenes enunciados en el artículo 16. Sin embargo, esta norma fue revisada por la Corte Constitucional, quien en desarrollo de sus competencias, efectuó la revisión de constitucionalidad del Acto Legislativo 01 de 2017, y así, en la sentencia C-674 de 2017, estimó que los incisos 2 y 3 del referido artículo 16 resultaban inconstitucionales, es decir, que se declaró la inexequibilidad de la norma que otorgaba competencia a la JEP para hacer comparecer a los terceros civiles no combatientes responsables de graves delitos y violaciones a los Derechos Humanos.

La Corte Constitucional adoptó esa decisión considerando que el artículo 16 sometió a los terceros civiles a un órgano judicial creado ex post y ad hoc. Señaló la Corte que la JEP no es apenas una nueva instancia de juzgamiento, sino que es una nueva institución, una nueva jurisdicción, que no pertenece a la rama judicial ni a la justicia ordinaria, con objetivos y lógica sustancialmente diferente, y además, creada a partir del diseño surgido con ocasión del Acuerdo Final celebrado entre el gobierno y las Farc-EP, lo que, a juicio de la Corte, permite concluir que se vulneran las garantías de independencia e imparcialidad, derivadas de la garantía de juez natural, que se desconoce al extender este diseño a terceros civiles no combatientes. Además, agregó la Corte, que los terceros civiles estarían sometidos a un régimen jurídico sustantivo distinto, que ofrece amplios márgenes de discrecionalidad al operador judicial ${ }^{37}$.

En este sentido, la Corte señaló:

"Aunque en principio la creación de una instancia ad hoc y ex post según las directrices de un acuerdo de paz suscrito entre el gobierno nacional y uno de los combatientes en el conflicto armado podría ser admisible en el presente escenario de transición de cara a la garantía del juez natural, lo es unicamente en relación con los combatientes, pero no para someter de manera forzosa a los demás actores, y en particular, a los no combatientes, como los terceros civiles, los agentes del Estado que no integran la fuerza pública, $y$ los propios aforados constitucionales. Asi las cosas, la creación de tribunas ex post, la inexistencia de un marco o referente preciso para cumplir su rol de investigar, juzgar $y$ sancionas las graves violaciones a los derechos humanos y las infracciones al Derecho Internacional Humanitario, y la configuración ad hoc de tales instancias que las expone a ser estructuralmente tendenciosas y parciales, si bien puede justificarse en un escenario

37 Corte Constitucional de Colombia. Sentencia C-674 de 2017. 
transicional orientado a la consecución de la paz, impide extender su competencia a los terceros civiles, por los delitos cometidos en el marco del conflicto armado"38.

Por lo anterior, la Corte Constitucional sustrajo de la competencia de la JEP la posibilidad de hacer comparecer a terceros civiles no combatientes para efectos de su investigación, juzgamiento y sanción, reiterando la competencia de la jurisdicción ordinaria con relación a las conductas punibles que aquellos hubieren incurrido durante el conflicto. Sin embargo, consideró admisible que, mediante la comparecencia voluntaria de los terceros civiles no combatientes, la JEP pueda asumir competencia para investigar, juzgar y sancionar las conductas de estos actores, para que puedan acceder a los beneficios que esa jurisdicción ofrece, bajo el pleno sometimiento al sistema de condicionalidades previsto.

Así las cosas, si bien la JEP perdió la competencia para vincular de forma obligatoria a los terceros civiles, por otra parte, la mantuvo para investigar, juzgar y sancionar a estos actores siempre que la comparecencia a esta jurisdicción haya sido voluntaria por parte de los mismos. Los requisitos contenidos en el Acto legislativo para admitir la vinculación de estos actores al SIVJRNR son dos, a saber: i) que no formaban parte de los grupos armados y ii) que hubieran contribuido de manera directa o indirecta a la comisión de delitos en el marco del conflicto.

Vale resaltar que, en una decisión del 7 de mayo de 2018, donde se decidió la solicitud de sometimiento voluntario del ex congresista David Char Navas, la Sala de Definición de Situaciones Jurídicas de la JEP, agregó que cuando se trata de conductas de financiación u otro tipo de colaboración, la JEP debe verificar, además: i) que las conductas a investigar no hayan sido resultado de coacciones, ii) que quien busca el sometimiento haya tenido una participación activa o determinante en crímenes competencia de la JEP, y iii) que las contribuciones realizadas por terceros a los grupos armados ilegales no hayan tenido el solo propósito de obtener un beneficio personal, propio o de un tercero. Posteriormente la sala de Sección de Apelación de este Tribunal, mediante auto de 21 de agosto de 2018, revocó esta decisión en especial en lo referente al último de los requisitos planteados, señalándose que no se debía rechazar la solicitud de sometimiento a la JEP presentada por el señor Char Navas, con el argumento de que las presuntas conductas delictivas cometidas por este hubiesen estado mediadas por la motivación de obtener un provecho o beneficio personal, pues

38 Corte Constitucional de Colombia. Sentencia C-674 de 2017. 
el artículo 16 del Acto Legislativo 01 de 2017, al definir la competencia de la JEP sobre terceros civiles, no incorpora consideraciones relativas a la motivación de la conducta ${ }^{39}$.

Adicionalmente, la Ley No 1.957 de 2019, ley estatutaria de la JEP, fijó como fecha límite el 6 de septiembre de 2019 para que los terceros civiles radicaran su solicitud de sometimiento voluntario a la jurisdicción, sin perjuicio de aquellos terceros que posteriormente sean vinculados a investigaciones en la jurisdicción ordinaria y deseen someterse a la JEP. En su comunicado 127 de 2019 (9 de septiembre de 2019), la JEP informó que 657 terceros civiles solicitaron su sometimiento a esta jurisdicción, de las cuales 540 solicitudes son de terceros y 117 son de agentes del Estado no miembros de la fuerza pública, entendiendo por tercero "la persona que no hizo parte de una organización o grupo armado, pero que contribuyó a la comisión de conductas relacionadas con el conflicto armado". A la fecha, se desconoce información disgregada sobre cuántos de estos terceros son empresarios o empresas.

\section{Comentarios Finales}

El abordaje de la responsabilidad corporativa en procesos transicionales es una tarea de difícil envergadura y con resultados dispares en las experiencias internacionales. Como se desarrolló en las páginas anteriores, en términos generales, los procesos transicionales han buscado, con poco éxito, la judicialización de las empresas que han participado en crímenes o violaciones a los Derechos Humanos. Mejor balance se ha mostrado con mecanismos extrajudiciales como las Comisiones de Verdad, aunque con bastantes limitaciones derivadas de la propia naturaleza de estos organismos.

En el caso colombiano, la primera experiencia de justicia transicional que se adelantó con la Ley de Justicia y Paz, evidenció una absoluta fragmentación entre la justicia transicional y la justicia ordinaria, por cuanto a la primera no se le dio competencia para la investigación, judicialización y sanación de actores corporativos. Esto generó que la justicia transicional solamente pueda abordar el problema a partir de las construcciones de contextos, y siempre compulsando copias a la justicia ordinaria para que allí se investigue y sancione a los responsables. Las cifras muestran que, salvo algunos casos emblemáticos, en términos

39 Cfr. República de Colombia. Tribunal para la Paz. Sección De Apelación. Auto TP-SA 19 de 2018, 21 de agosto de 2018. Radicado Interno: No 20181510021592. 
generales, la justicia ordinaria ha sido incapaz de enfrentar la magnitud del fenómeno.

En la segunda experiencia transicional, se planteó la creación de un organismo con competencia para investigar, juzgar y sancionar a los terceros civiles responsables de graves crímenes durante el conflicto. El fallo de la Corte Constitucional redujo esta posibilidad al sometimiento voluntario de los terceros a la JEP, manteniendo en la justicia ordinaria la competencia y el deber de investigar y sancionar a estos actores. Esto genera, nuevamente, una fragmentación de los sistemas de justicia en tanto, de nuevo, la justicia transicional solamente podrá compulsar copias a la justicia ordinaria respecto a terceros civiles, en los casos que no exista sometimiento voluntario por parte de aquellos.

Esto nos coloca en un escenario medio de autorregulación y judicialización. Los terceros civiles, y entre ellos los actores corporativos, deberán evaluar las virtudes y consecuencias que tendrá su decisión de someterse o no voluntariamente a la JEP. El análisis debe ser realizado no solo en términos de costo-beneficio (económico, jurídico, político, social), sino que se esperaría que los actores empresariales asuman un verdadero rol ético y que, en desarrollo de los principios autorreguladores de la actividad empresarial, se comprometan con verdaderos procesos de verdad, justicia, reparación y no repetición, a cambio, por supuesto, de los beneficios punitivos propios de un escenario de justicia transicional. Seguramente, esto solo tendrá lugar si el ejercicio de judicialización de estos actores, a cargo de la justicia ordinaria, se fortalece: los actores económicos solamente se verán motivados a realizar este ejercicio de costo-beneficio si existe la certeza de un claro e inexorable estimulo negativo, que en este caso es la judicialización dentro del marco de la justicia ordinaria sin los beneficios correspondientes.

Es imposible realizar ahora un balance sobre el éxito o fracaso de esta dinámica de sometimiento voluntario. La JEP recibió 540 solicitudes de sometimiento voluntario provenientes de terceros, lo cual no quiere decir que todas ellas serán admitidas, pues la Sala de Definición de Situaciones Jurídicas de la JEP deberá decidir caso a caso cuáles cumplen los requisitos de ingreso a la jurisdicción. También se desconoce cuántas de estas solicitudes son de personas vinculadas al sector productivo y de empresas. Pero si compara esta cifra con el número de terceros civiles a los que se han compulsado copias bajo la Ley de Justicia y Paz (311 terceros civiles), se puede observar que las cifras no están muy lejanas entre sí, lo que indicaría que el ejercicio de sometimiento voluntario podría llegar a arrojar buenos resultados dentro de la justicia transicional. 
Para que las dinámicas de autorregulación y sometimiento voluntario arrojen buenos resultados, es importante que la JEP no establezca limitaciones adicionales o excesivas a las contempladas en el Acto Legislativo para el ingreso a la jurisdicción de terceros civiles no combatientes. Exigencias como "que las contribuciones realizadas por terceros a los grupos armados ilegales no hayan tenido el solo propósito de obtener un beneficio personal, propio o de un tercero", pueden resultar extremadamente problemáticas para el caso de la vinculación de actores corporativos, pues en la mayoría, sino en todos los casos, las actividades de aquellos están motivadas en lograr un beneficio en el desarrollo de su actividad empresarial ${ }^{40}$. En tal sentido, resulta afortunada la decisión de la Sección de apelación de este tribunal, en la que se indica que este no es un factor a tomar en cuenta para decidir la admisión o no de una solicitud de sometimiento voluntario.

Finalmente, vale resaltar que el Acuerdo Final para la Paz contempló la creación de una Comisión de Esclarecimiento de la Verdad como un mecanismo extrajudicial que pretende, entre otros objetivos, promover y contribuir al reconocimiento voluntario de responsabilidades individuales y colectivas de todos aquellos que directa o indirectamente participaron en el conflicto. Este será un escenario paralelo y complementario al judicial, para que se establezcan criterios de verdad sobre escenarios de macrocriminalidad y de esclarecimiento de patrones de violencia, en los cuales hayan participado actores corporativos.

\section{Bibliografía CITADA}

Bernal-Bermúdez, Laura (2017): “The power of business and the power of people: understanding remedy and business accountability for human rights violations - Colombia 1970 - 2014" (St Antony's College, DPhil in Sociology) (Fecha de consulta: 20 de agosto de 2019). (Disponible en: https://ora. ox.ac.uk/objects/uuid:f211a449-8222-4fbb-8a53-07abc6add43c).

Centro Internacional de Toledo para la Paz (CITpax)-Colombia (2018): La verdad en las sentencias de justicia y paz. Un estudio cuantitativo sobre los hechos, sus principales narradores y las redes de apoyo develadas (Bogotá, Centro Internacional de Toledo para la Paz-CITpax).

40 Michalowski et al. (2018), p. 194. 
Comité Internacional de la Cruz Roja (2006). "Empresas y DIH: preguntas y respuestas". (Fecha de consulta: 15 de agosto de 2019). (Disponible en: https://www.icrc.org/es/doc/resources/documents/misc/business-ihlquestions-answers.htm).

Hernández Zubizarreta, J. y Ramiro, P. (2015): Contra la lex mercatoria. Propuestas y alternativas para desmantelar el poder de las empresas transnacionales (Barcelona, Icaria).

Justicia Especial para la Paz JeP (2019). “Jurisdicción Especial para la Paz”. (Fecha de consulta: 27 de agosto de 2019). (Disponible en: https://www.jep. gov.co/Paginas/JEP/Jurisdiccion-Especial-para-la-Paz.aspx).

KosKA, Geeta (2016): "Corporate accountability in times of transition: the role of restorative justice in the South African Truth and Reconciliation Commission", en Restorative Justice, 4:1, 41-67.

Meetali, Jain y Bonita, Meyersfeld (2014): "Lessons from Kiobel V Royal Dutch Petroleum Company: Developing Homegrown Lawyering Strategies Around Corporate Accountability", en South African Journal on Human Rights, 30:3, 430-457.

Michalowski, Sabine; Cardona, Juan Pablo (2015): "Responsabilidad corporativa y justicia transicional”, en Anuario de Derechos Humanos, (11), pp. 173-182.

Michalowski, Sabine; Carranza, Rubén (2014): “Conclusion”, en Michalowski, Sabine, Corporate Accountability in the Context of Transitional Justice (Londres, Routledge).

Michalowski, Sabine; SÁnchez León, Nelson Camilo; Marín López, Daniel; Jiménez Ospina, Alejandro; Martínez Carrillo, Hobeth; Domínguez MaZHARI, Valentina; ARroyave VelásqueZ, Lina (2018): Entre coacción y colaboración. Verdad judicial, actores económicos y conflicto armado en Colombia. (Bogotá, Centro de Estudios de Derecho, Justicia y Sociedad, Dejusticia).

Muñoz, Santiago (2010): "Fundamentos e instrumentos jurídicos de la regulación económica”, en Muñoz Machado, Santiago (director), Derecho de la regulación económica, Fundamentos e instituciones de la Regulación, Volumen 1 (Madrid, Iustel), pp. 15-244.

PaYne, Leigh A. (2017): "Complicidad corporativa y justicia transicional: preparando la escena”, en Van de Sandt, Joris y Moor, Marianne (editores), La Paz, responsabilidad de todos (Utrecht, Pax), pp. 20-55. 
Prandi, María y Lozano, Josep M. (2010): La RSE en contextos de conflicto y postconflicto: de la gestión del riesgo a la creación de valor (Barcelona, Escola de Cultura de Pau (UAB)/ Instituto de Innovación Social (ESADE)).

SÁnchez León, Nelson Camilo, Marín López, Daniel (2017): "Responsabilidad Corporativa en la justicia transicional en Colombia", en Van de Sandt, Joris y Moor, Marianne (editores), La Paz, responsabilidad de todos (Utrecht, Pax), pp. 20-55.

Sandoval, Clara y Surfleet, Gill (2014): "Corporations and Redress in transitional Justice Processes”, en Michalowski, Sabine, Corporate Accountability in the Context of Transitional Justice (Londres, Routledge), pp. 93-113.

Sandoval, Clara; Filippini, Leonardo, y Vidal, Roberto (2014): "Linking Transitional Justice and Corporate Accountability", en Michalowski, Sabine, Corporate Accountability in the Context of Transitional Justice (Londres, Routledge), pp. 9-26.

SHARp, Dustin (2014): Justice and Economic Violence in Transition (Nueva York, Springer).

TOBAR, Jenner Alonso (2017): La autorregulación normativa de los actores privados en el comercio internacional: el caso de los Principios sobre los Contratos Comerciales de Unidroit. (Tesis de doctorado, Universidad de Buenos Aires). (Fecha de consulta: 15 de agosto de 2019). (Disponible en: http://repositoriouba. sisbi.uba.ar/gsdl/collect/posgrauba/index/assoc/HWA_2107.dir/2107.PDF)

VAn DE SAndt, Joris y Moor, Marianne (2017): La Paz, responsabilidad de todos (Utrecht, Pax).

\section{LEGISLACIÓN Y JURISPRUDENCIA CITADA}

República de Colombia, Acto Legislativo 01 de 2017.

República de Colombia. Tribunal para la Paz. Sección de Apelación. Auto TP-SA 19 de 2018, 21 de agosto de 2018. Radicado Interno: No 20181510021592.

Corte Constitucional de Colombia. Sentencia C-674 de 2017. 